\title{
Pusat Komunitas Gamer di Surabaya dengan Tema Metafora
}

\author{
Bima Pratama Fauzi Putra ${ }^{1}$, Wiwik Widyo Widjajanti ${ }^{2}$, Annisa Nur Ramadhani ${ }^{3}$ \\ 1,2,3 Jurusan Arsitektur, Fakultas Teknik Sipil dan Perencanaan, Institut Teknologi Ahdi Tama Surabaya \\ Email: ${ }^{1}$ bimprat1@gmail.com
}

\begin{abstract}
E-sport is a completion to play video games which are generally conducted between professional players. In Surabaya, game players are increasing every day since there was a news about various games which were entering to the E-sport branch in Asie Games in 2018. But, increasing of technology development does not support with adequate facilities. It is a reason to build and design Gamer Community Center in Surabaya. Parents concern to their children who like to play games and the bad effects of games were the main problems. Parents and society ignorance about E-sport, as well as Surabaya government hasn't taken apart in the development of E-sport, was a problem which must be resolved. The presence oof designing and planning Gamers Community center was hoped that it will able to provide insight to the E-sport world to the society and it is able yo develop E-sport in Surabaya. This study used qualitative and survey methods, so, the researcher obtained adequate description of the design and the theme was metaphorical which was focused to the forms that reflect a function. It was also supported by gamer's adaptive macro concept which made the function and gamers' characteristics. Land arrangement of micro concept and forms used abstract metaphor combined with micro concept of hi-tech space. It would make an area become unique, comfortable, and capable to develop E-sport in Surabaya. It is hoped by using this design, the parents won't be worry to their children when their children love to play game. Because game becomes as a profession.
\end{abstract}

Keywords: zE-sport, Surabaya, Community, Gamers, Metaphors, Game

\begin{abstract}
Abstrak. E-sport adalah kompetisi bermain video game, yang pada umumnya dilakukan antara para permian profesional. Jumlah Gamer yang ada di Surabaya kian hari kian bertambah sejak adanya berita tentang berbagai judul game masuk kedalam cabang e-sport di Asian Game 2018. Namun, meningkatnya perkembangan teknologi dan minat masyarakat terhadap e-sport, tidak didukung dengan fasilitas yang memadai. Kekawatiran orang tua terhadap anak yang gemar bermain game serta dampak buruk yang ditimbulkan terhadap anak, dirasa menjadi permasalahan utama. Ketidak tauan para orang tua dan masyarakat tentang e-sport, serta belum ikut andilnya pemerintah Surabaya dalam perkembangan e-sport, merupakan suatu permasalahan yang harus di selesaikan. Dengan hadirnya Perencanaan dan Perancangan Pusat Komunitas Gamer di Surabaya ini, diharapkan mampu memberikan wawasan tentang dunia e-sport kepada masyarakat serta dapat mengembangkan e-sport yang ada di Surabaya. Menggunakan metode kualitatif dan survey, sehingga diperoleh gambaran tentang desain yang cukup memadai dalam perancangan, dengan tema metafora yang berfokus pada bentukan yang mencerminkan suatu fungsi. Hal ini juga didukung dengan konsep makro adaptif gamer yang lebih mendekatkan fungsi dengan sifat para gamer, mikro konsep tatanan lahan dan bentuk yang menggunakan metafora absrak dipadukan dengan konsep mikro ruang hi-tech dirasa akan menjadikan suatu kawasan yang unik, nyaman dan tentu saja mampu mengembangkan serta memajukan E-sport yang ada di Surabaya. Diharapakan dari hasil rancangan ini maka tidak ada lagi kekawatiran orang tua tentang kegemaran anak akan game, karena game kini juga bisa menjadi profesi.
\end{abstract}

Kata Kunci: E-sport, Surabaya, Komunitas, Gamer, Metafora. Game

\section{Pendahuluan}

Pada era modern dengan teknologi yang sangat berkembang, orang-orang menggunakan internet sebagai sarana mencari informasi serta sebagai sarana mencari penghasilan. Salah satu nya dengan bidang e-sport (Electronic Sport), permainan e-sport sebagai sarana permainan juga semakin diminati oleh masyarakat karena beberapa pengembangan teknologi yang semakin maju serta akses yang mudah sehingga mendukung para gamer e-sport. 
Dengan adanya 3 asosiasi e-sports di Indonesia yang bentuk oleh Komunitas gaming dari berbagai kalangan, baik dari game provider, forum Komunitas game, dan juga beberapa klan gaming di Indonesia. Asosiasi ini akan menjadi wadah Komunitas gamer Indonesia, khususnya mereka yang tertarik untuk mengembangkan diri dan meraih prestasi tertinggi di e-sports. Perkembangan di bidang game, juga di dapati di kota Surabaya. Jumlah gamer yang ada di Surabaya kian hari kian bertambah sejak adanya berita tentang berbagai judul game masuk kedalam cabang e-sport di Asian Game 2018, dan e-sport sendiri ikut di pertandingkan dalam seagame. (Hansen and Kwanda, 2016)

Surabaya merupakan kota yang memiliki banyak mahasiswa di berbagai tempat seperti Sekolah, mall, dan universitas. Mereka memiliki berbagai kegiatan dan salah satunya adalah $e$-sport. Surabaya juga memiliki fasilitas yang dapat mendukung adanya fasilitas $e$-sport. Koneksi internet telah tersedia di Surabaya dengan berbagai pilihan jaringan dan kualitas. Untuk melakukan $e$-sport juga belum ada tempat yang terpusat karena tidak semua game center memfasilitasi berbagai macam. Fasilitas yang ada juga tidak sama dan sering didapatkan game center yang tidak sesuai kebutuhan pelaku e-sport. Namun bukan itu saja, di Surabaya sendiri kita sering mendapati anak di bawah umur hingga larut malam masih bermain game di warung kopi yang menyediakan wifi. Hanya dengan bermodal memesan segelas air minum meraka dapat menikmati fasilitas wifi yang ada di warung kopi dekat dengan rumah. Banyak sekali orang tua yang terkadang marah akan kelakukan anaknya ini. Sehingga kepedulian ini muncul.

Dengan adanya perencaan dan perancangan pusat Komunitas gemer di Surabaya ini menjadi wadah bagi anak-anak yang ingin bermain game dengan menyediakan akses wifi gratis dan juga tempat yang nyaman bagi anak-anak berusia 9-18 keatas untuk bermain. Serta tidak luput juga dengan kehadirannya Percangan dan Perencanaan Pusat Komunitas Gamer di Surabaya, di harap dapat menjadi wadah bagi meraka yang ingin fokus terjun dalam bidang $e$-sports dan ingin menjadi pro player ataupun menjadi cester.

\subsection{Maksud dan Tujuan}

Perencanaan dan Perancangan Pusat Komunitas gamer di Surabaya bermaksud untuk memberikan wadah bagi para gamer di Surabaya untuk ikut andil dalam ajang E-sport dan juga mengenalkan dunia E-sport lebih jauh lagi. dan memeberikan arahan bagi anak-anak untuk dalam bermain game dengan bijak serta bertujuan untuk menjadikan wadah tukar pikiran bagi para gamer, mengilangkan kekuatiran orang tua kepada anaknya saat bermian game, memberikan pengetahuan hal positif di bidang game, membukakan jalan bagi gamer pemula menuju ke espoert, memberikan arahan bagi para gamer saat berprilaku dengan baik ketik bermain game.

\section{Tinjauan Pustaka}

\subsection{Arsitektur Metafora}

Arsitektur Metafora merupakan ungkapan sebuah visual suatu objek tertentu yang di aplikasikan ke sebuah bentukan bangunan. Sehingga mencerminkan fungsi dari bangunan tersebut. Metafora juga merupakan teknik untuk mentransfer subjek atau deskripsi sesuatu menjadi sesuatu yang lain, bisa keseluruhan atau sebagian saja dari unsur- unsurnya. Dalam hal ini metafora berupaya untuk menemukan unsur- unsur dari suatu subjek, kemudian ditransfer ke unsur-unsur subjek yang lain. (Darussalam, 2019)

\subsection{Perencanaan dan Perancangan Pusat Komunitas Gamer di Surabaya}

Perencanaan dan Perancangan Pusat Komunitas Gamer di Surabaya adalah wadah berkumpulnya suatu kelompok yang mempunyai ketertarikan hobi bahkan sampai fanatik terhadap game.

\section{Metode Penelitian}

Metedologi yang akan digunakan merupakan metodologi perencanaan dan perancangan. Metodologi merupakan cara pendekatan dan menggambarkan alur berpikir dalam memecahkan masalah, sehingga dapat digambarkan dalam sebuah diagram, tetapi metodologi bukan langkah-langkah penelitian, melainkan dasar bagi peneliti untuk menjalani langkah-langkah penelitian. Sehingga metode penelitian adalah salah satu faktor penting yang dapat membantu pelaksanaan perencanaan dan perancangan ini. 


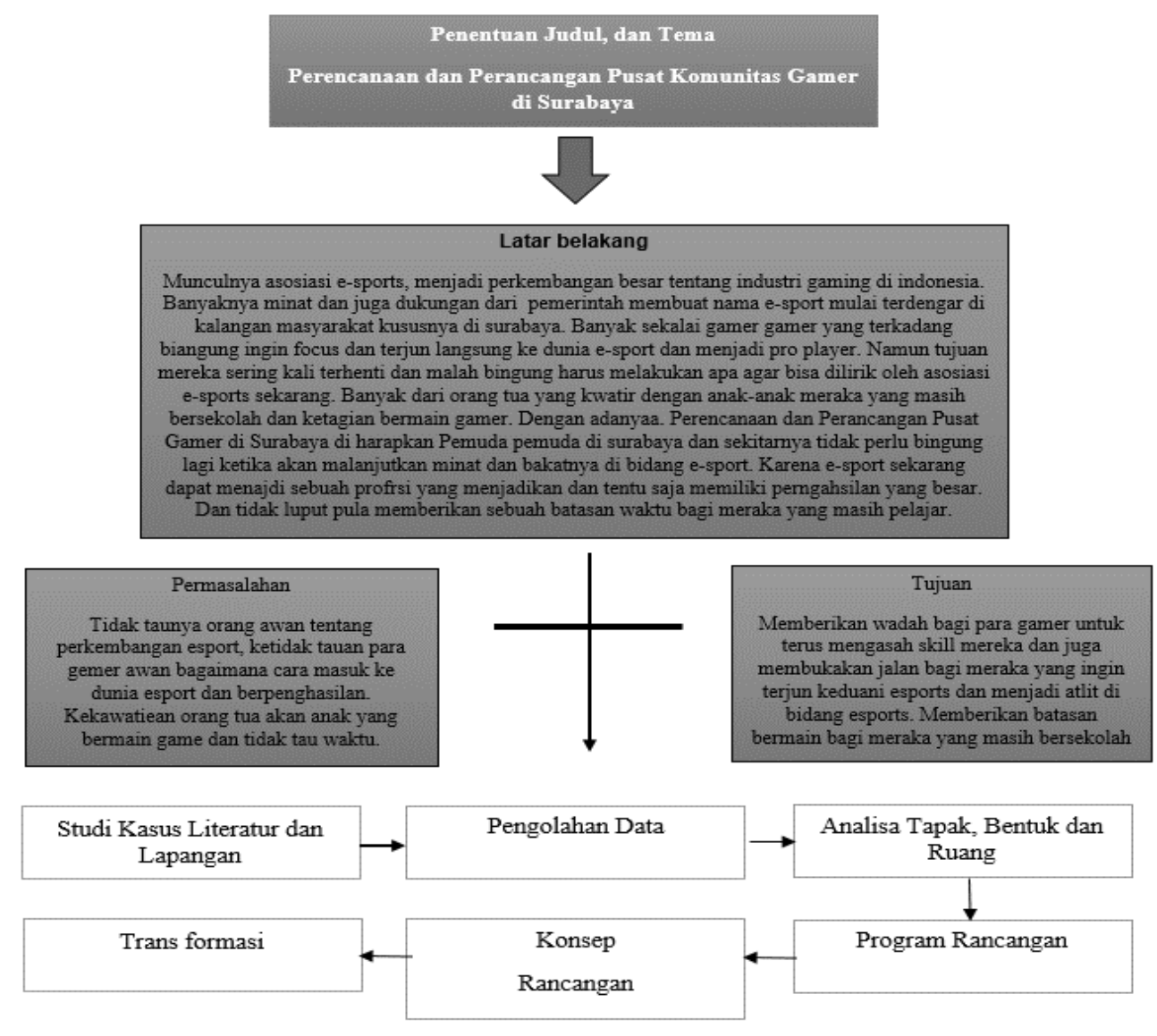

Gambar 1. Kerangka bagan metodelogi

\section{Hasil dan Pembahasan}

Dalam pembahasan disini dapat membandingkan studi kasus lapangan dan studi literatur yang diperoleh, sehingga dapat memberikan referensi dan pemahaman lain dari luar bangku perkuliahan terhadap proyek yang akan direncanakan yaitu "Perencanan dan Perancangan Pusat Komunitas Gamer di Surabaya". dengan tema Arsitektur Metafora. Pengumpulan data pada studi kasus literatur didapatkan dengan mencari di text book, jurnal ilmiah, dan melalui media internet. Obyek-obyek tersebut akan dikaji sebagai berikut:

Untuk studi kasusu lapangan yang dilakukan menggunakan TNC-SOLO Poseidon Game Center, Solo dan NXL E-sport Center, Jakarta menyangkup seluruh kajian arsitektur yang ada di setiap studi kasus lapangan. Pada studi kasusu literatur mengambil E-sport Stadium Arlington, Notrh Amerika dan juga ruang dan Allied E-sports Arena Las Vegas. Nevada Amerika Serikat Studi Kasus Literatur mengambil aspek tatanan lahan bentuk pada BSD City, Tanggerang Banten hanya mengadaptasi dari segi tatanan lahanya saja.

\subsection{Program Ruang}

Program ruang (programming) didefinisikan sebagai "Suatu proses peng-identifikasian dan pendefinisian kebutuhan-kebutuhan perancangan (the design needs) dan peng-komunikasian permintaan-permintaan klien kepada Perancang" Aspek-aspek ruang yang harus dijelaskan berdasarkan kebutuhan ruang, besaran ruang, organisasi ruang, diagram ruang, dan persayaratan ruang. Dari aspek tersebut dipengaruhi dari sebuah aktivitas yang terjadi dari berbagai obyek atau bangunan yang ada. Aktifitas tersebut yang dibutuhkan dalam memprogram sebuah ruang, dari ukuran atau dimensi ruang, 
sirkulasi, penataan perabot, penataan massa dan unsur-unsur lainya yang berkaitan dengan program ruang (Hansen and Kwanda, 2016).
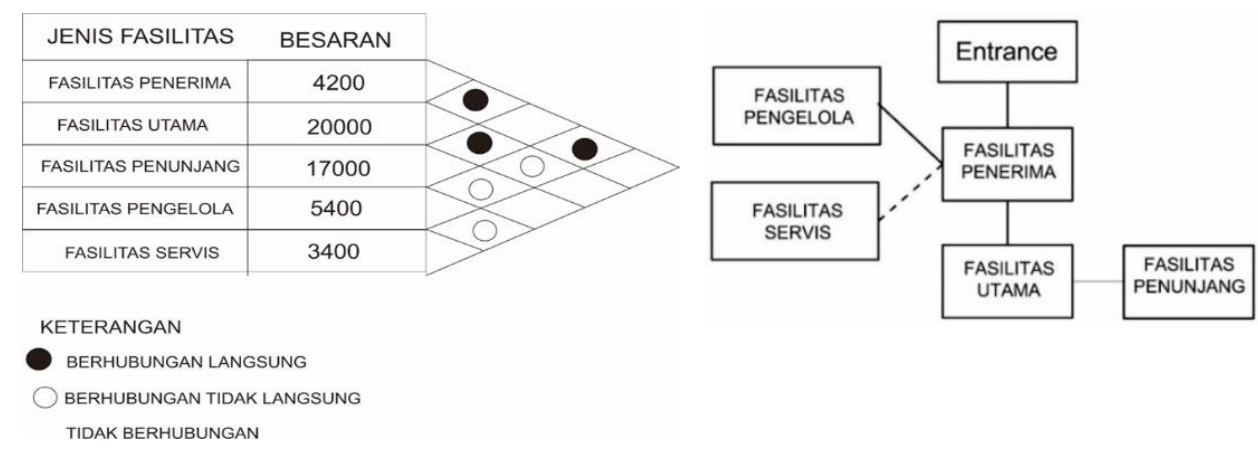

Gambar 2. (kiri) Total besaran ruang; dan (ksnsn) Hubungan ruang

\subsection{Tatanan Lahan}

Lokasi tapak yang akan digunakan dalam merancang Komunitas Gamer di Surabaya, berada di jalan Pantai kenjeran, Kelurahan Kenjeran, Kecamatan Bulak, Kota Surabaya.

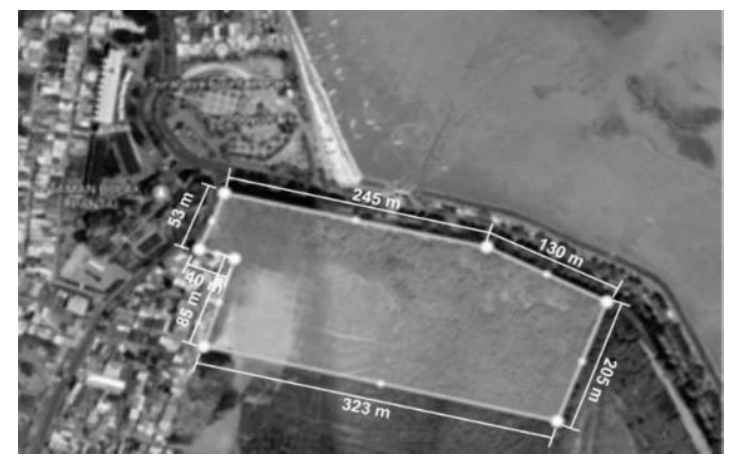

Gambar 3. Lahan yang dipilih

Lokasi tapak/site memiliki batas-batas dengan lahan milik orang lain atau instansi terkait. Berikut adalah batas - batas dari lokasi site yang diambil:

Batas Utara : Pantai Kenjeran/Selat Madura

Batas Timur : Pantai Kenjeran

Batas Selatan : Pemukiman penduduk

Batas Barat : Pemukiman penduduk

Dari hasil beberapa kajian tentang analisis tapak yang dapat disimpulkan beberapa pertimbangan dalam melakukan suatu proses Perencanaan dan Perancangan Pusat Gamer di Surabaya. Beberapa kesimpulan diantaranya adalah:

Dari hasil kajian analisis klimatologi, penataan massa bangunan menyesuaikan dengan kondisi iklim disekitar tapak/site dengan tujuan dapat memaksimalkan potensi dari iklim yang terjadi terhadap tapak/site. Hasil kajian Sirkulasi, memunculkan gambaran secara umum bagaimana akses untuk mencapai ke tapak/site dan bagaimana sirkulasi didalamnya. Hasil kajian kebisingan, memunculkan gambaran secara umum tentang bagaimana penataan bangunan dan vegetasi untuk meredam dan memantulkan kebisingan yang terjadi di jalan raya. Hasil kajian analisis landsekap, penataan tanaman atau tumbuhan yang ada pada tapak/site menyesuaikan tumbuhan yang hidup disana dengan ditambah beberapa tanaman dan pepohonan dan memanfaatkan beberapa tanaman sebagai bagian dari estetika pada site.

Dari hasil kajian analisis view, dapat disimpulkan penataan bangunan yang yang memiliki view lebih menonjol diletakkan pada posisi yang strategis agar dapat dijangkau oleh pandangan masyarakat yang lewat dan juga penglihatan menuju luar lebih imajinatif. Hasil beberapa pertimbangan diatas 
menghasilkan suatu progres berlanjut yaitu penzoningan yang fungsinya untuk meletakkan bangunanbangunan berdasarkan zona dan fungsinya agar antara bangunan satu dengan bangunan lainnya mempunyai keterkaitan yang kuat baik dari segi fungsi maupun estetikanya.

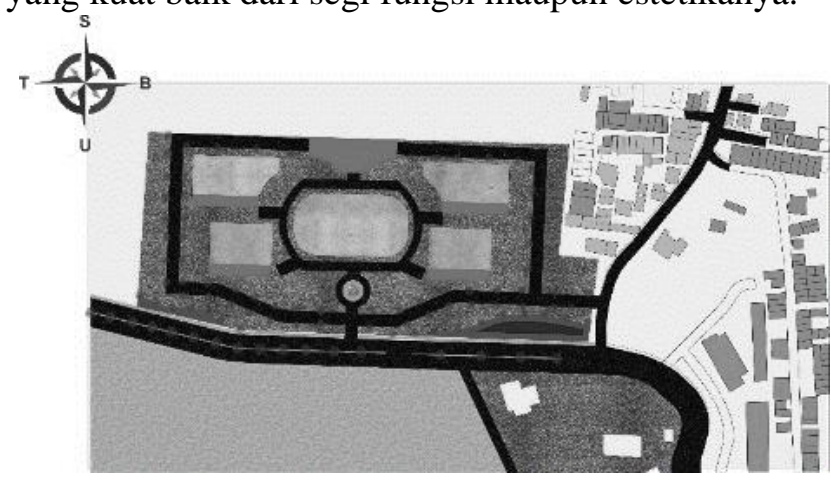

Gambar 4. Site Plan Rancangan

\subsection{Program Rancangan}

Berdasarkan hasil studi banding pada studi lapangan dan studi literatur, terdapat kelebihan dan kekurangan dari setiap objek studi sehingga dapat tercipta program rancangan yang baik dan sesuai dengan yang diharapkan. Suatu program rancangan selalu berkaitan dengan tema. Tema pada rancangan berfungsi sebagai konsep awal yang menentukan gambaran bangunan yang akan didesain.

Berdasarkan dari data dan hasil analisis yang telah dilakukan, maka didapatkan partial ide sebagai berikut :

\section{Partial Idea Tatanan Lahan}

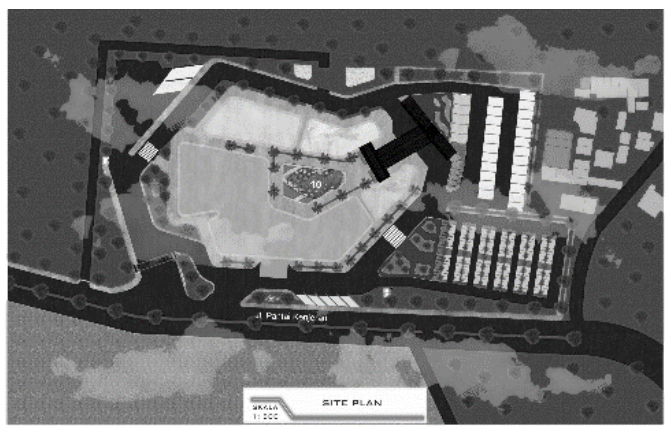

Gambar 5. Partial ide tatanan lahan

Membuat tatanan lahan yang berkesinambungan dengan tema arsitektur metafora membuat gambaran sebuah konsol yang di tata sedemian rupa hingga menjadi sebuah tatanan lahan yang unik dan menciptakan tatanan lahan yang berkesinambungan dengan bangunana yang ada.

\section{Partial Idea Tatanan Bentuk}

Merencanakan sebuah bentuk dengan penerapan Aspek Arsitektural yang simbolis dan berkesinambungan dengan Tema Arsitektur Metafora

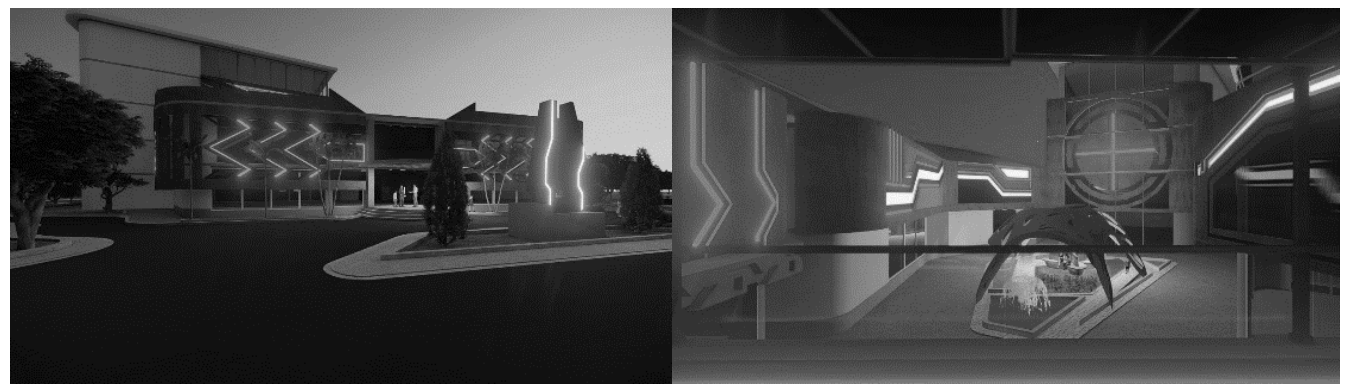




\section{Gambar 6. (kiri) Partial ide bentuk utama; dan (kanan) icon simbolis bangunan utama}

Penerapan fasad dengan garis lampu memberikan kesan bangunan teknologi. Aksen garis dibuat menyerupai lajur komponen yang mengarah ke inti bangunan dan penerapan bangunan yang adaptif dengan lingkungan sekitar.

\section{Partial Idea Tatanan Ruang}

Merencanakan sebuah ruang dengan urutan tata ruang dan suasana ruang yang berkesinambungan dengan fungsi ruang yang maksimal dengan tema hi-tech yang mengutamakan teknologi didalam ruangan.

Menerapkan tatanan ruang yang tidak membingungkan pengunjung dengan berurutannya setiap fungsi, mulai dari bagia depan ruang gaming, ruang konsol, ruang gaming handphone, penerapan sebuah suasana ruang yang modern dengan aksen garis lampu dengan penerapan konsep hi-tech.

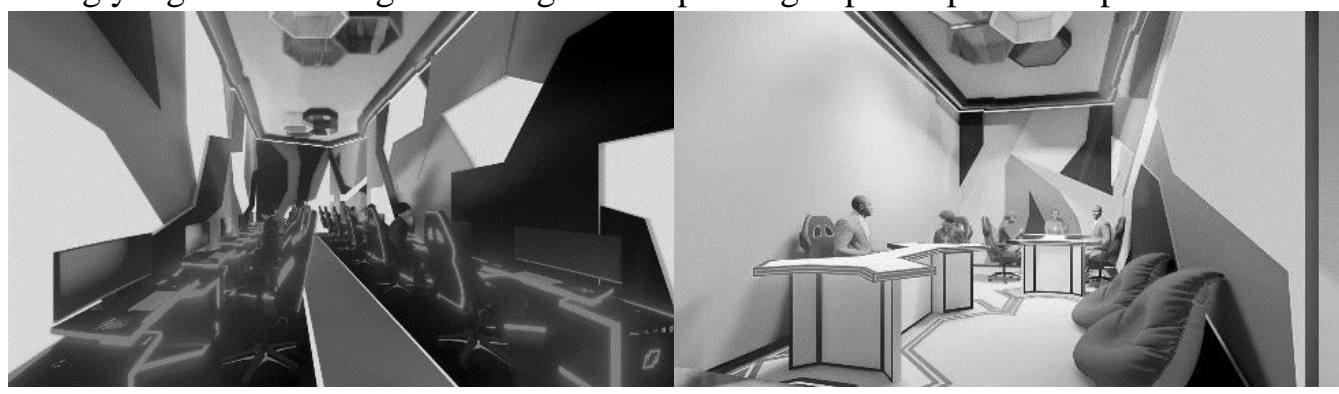

Gambar 7. (kiri \& kanan) Partial ide ruang gaming $p c$ dan $h p$

\section{Konsep Rancangan}

a. Tema "Arsitektur Metafora”, Arsitektur Metafora ialah teknik untuk mentransfer subjek atau deskripsi sesuatu menjadi sesuatu yang lain, bisa keseluruhan atau sebagian saja dari unsurunsurnya. Dalam hal ini metafora berupaya untuk menemukan unsur- unsur dari suatu subjek, kemudian ditransfer ke unsur-unsur subjek yang lain. Jadi pada dasarnya Arsitektur Metafora merupakan ungkapan sebuah visual suatu objek tertentu yang di aplikasikan ke sebuah bentukan bangunan. Sehingga mencerminkan fungsi dari bangunan tersebut (Darussalam, 2019).

b. Makro Konsep "Adaptif Gamer", adalah upaya untuk menyesuaikan tatanan lahan, bentuk dan ruang pada objek peracangan pusat Komunitas game yang di adaptasi dari prilaku para gamer dengan pengaplikasian tatanan lahan, bentuk dan ruang. sehingga menimbulkan kenyaman bagi para gamer yang ada

c. Mikro Konsep Tatanan Lahan "Metafora Abstrak", pada bentukan bangunan sendiri, masih pada sebuah visual suatu objek yang diaplikasikan ke bentukan perencanaan pusat Komunitas gamer yang di ambil dari unsur suatu game itu sendiri, bisa konsol suatu game. bisa juga tema pada judul game tertentu.

d. Mikro Konsep Bentuk “Abstrak", di mana penataan tatanan lahan yang menekankan sebuah imajinasi yang bebas, dengan penerapan bentukanbangunan yang mengarah ke sebuah bentukan absrak

e. Mikro Konsep Ruang "Hi-Tech", yang mana suatu ruang tentu menyesukan dengan fungsi dari bangunan itu sendiri. Bangunan yang bertemakan teknologi, menghadirkan ruang dengan konsep hi-tech yang melambangkan sebuh fungsi suatu banguan. dengan ditambah suatu teknologi yang lebih memudahkan pengunjung untuk melakukan aktifitasnya. (Hansen and Kwanda, 2016)

\section{Detail Struktur Arsitektur}

Pada bangunan ini menggunkan detail rangka atap baja ringain flat yang digabungkan dengan bengadopsi bentuk atap monopitch. Pemilihan tipe atap monopitch dilakukan karena bentukan atap monopitch dapat di atur untuk bentuk bangunan yang terbilang unik (Renansiva, 2018). Sehingga desain bentukan yang dimunculkan memiliki keseimbangan secara komposisi, mengingat mikro konsep bentuk 
yang diusung adalah "Abstrak" perlu diseimbangkan oleh komposisi bentuk yang berkesan sederhara, seperti efek yang dimunculkan oleh bentuk atap monopitch.
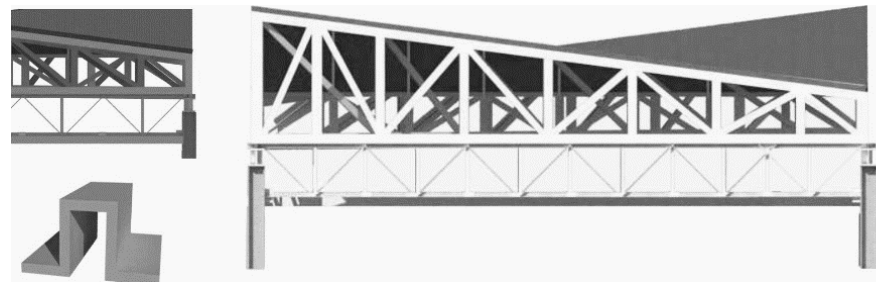

Gambar 8. Penerapan rangka atap

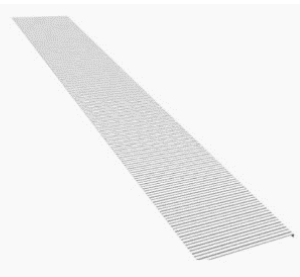

\section{Detail Sains Arsitektur}

Pada area bangunan dibuat sebuh lubang lubang sebagai pemecah hembusan angin, karena terletak di dekat pantai yang hebusan anginya kencang disini fasad juga membantu memecah hembusan angin. Untuk pencahaan menggunakan pencahaan alami di bangian penghubung anatar ruangan.

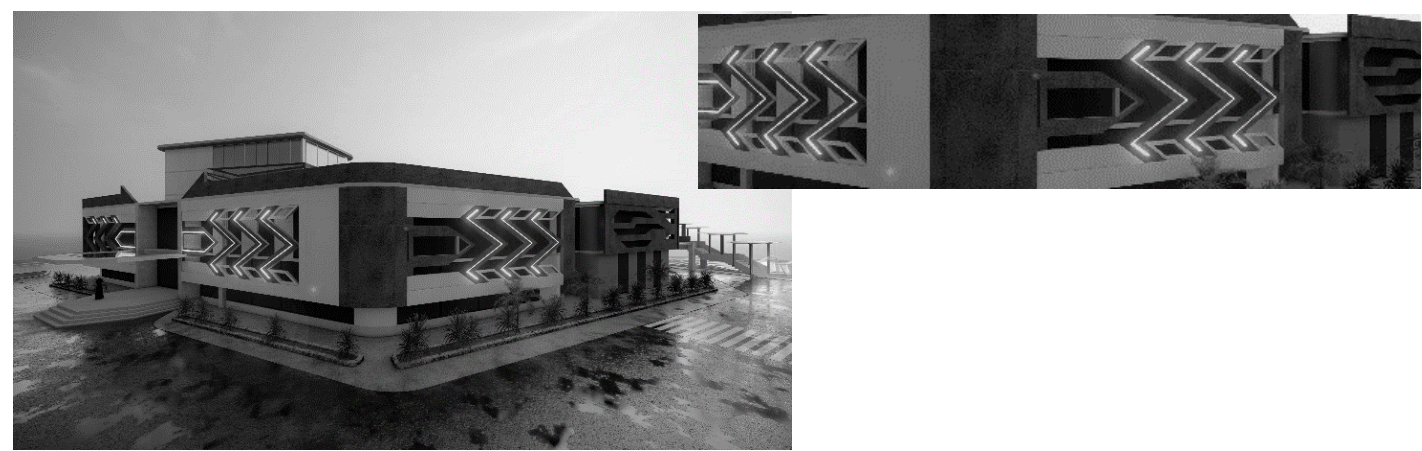

Gambar 9. Sains arsitektur penghawaan dan cahaya alami berasal dari fasad dan juga jendela

\section{Detail arsitektur dan lansekap}

Untuk segi fasad menggunakan aksen garis yang dibuat seolah aliran arus listrik yang menyelimuti fasad yang mengarah layaknya lajur listrik ke pusat bangunan. Lansekap disini di letakan pada area yang di lewati pengunjung guna penyejuk dan peneduh. (Widjajanti, 2010)

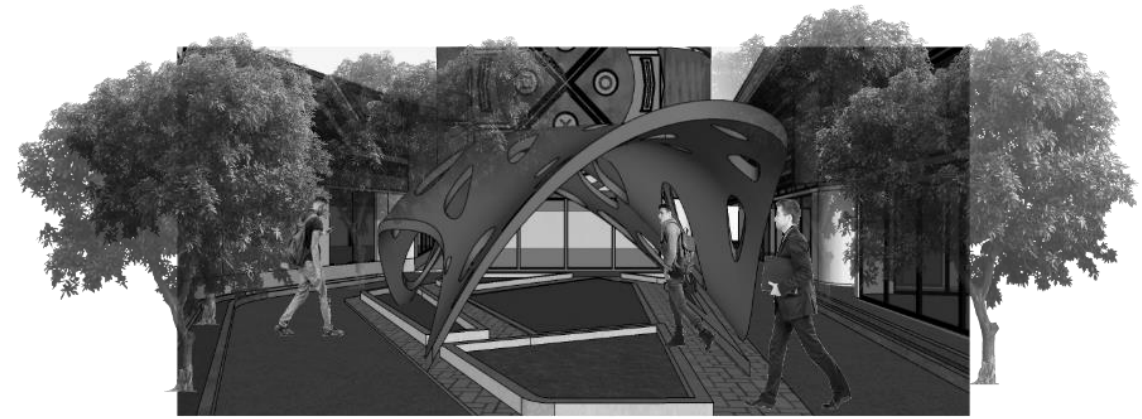

Gambar 10. Area taman tengah bangunan

Kesan rindang yang di ciptakan pada area tengah kawasan, membuat sausana yang berbeda dan menyejukan, area jalan setapak yang di berikan area pohon rindang dan juga tempat duduk guna pengunjung yang ingin menikmati suasana diluar bangunan. (Imansari and Khadiyanta, 2015) 


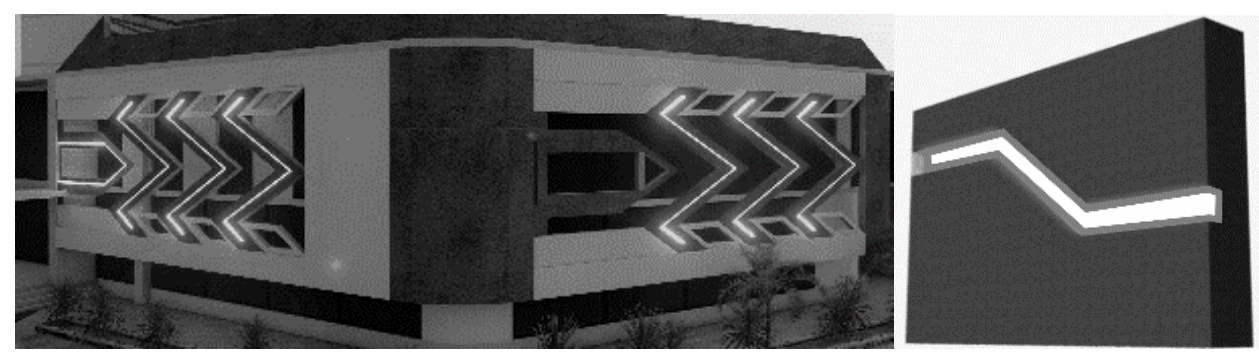

Gambar 11. Aksen garis pada bangunan

Bentuk bangunan sudah unik sehingga untuk memadukan dengan konsep bentuk, perlu diberikan fasad yang mencerminkan sebuah konsep metafora absrak. Dengan memberikan kesan jalur mesin yang di pandukan dengan model modern sehingga mencerminkan sebuah kesan bentuk jalur mesin. Disini jalur mesin diberikan aksen lampu LED sehingga membuatnya lebih modern dan mencerminkan bangunan teknologi.

\section{Kesimpulan}

Rangkuman disini mencakup kesimpulan agar mendapatkan hasil yang lebih maksimal. Tujuan dalam Pusat Komunitas Gamer di Surabaya adalah sebagai sarana dan prasarana para pemain game untuk mengembangkan kemampuan bermainnya, dan sebagai wadah pagi para gamer yang serius untuk terjun ke dalam dunia e-sport itu sendiri hingga menjadi pemain profesional.

Tetapi, minimnya fasilitas dan tempat turnamen yang menyebabkan keahlian organisasi terpendam dan tidak dapat berkembang terlebih lagi Kota Surabaya adalah salah satu kota terbesar di Provinsi Jawa Timur. Kota Surabaya ini juga termasuk kota terbesar ke dua setelah Kota Jakarta. Dari sinilah yang memotivasi saya merancang pembangunan Pusat Komunitas Gamer di Surabaya agar dapat mengembangkan dan meningkatkan kemampuan mereka dalam mengikuti ajang turnamen $E$-sport.

\section{Referensi}

Darussalam, M. (2019) 'Konsep Arsitektur', p. 153044.

Hansen, B. H. and Kwanda, T. (2016) 'Fasilitas Pelatihan Pemain E-sport', Edimensi Arsitektur, IV(2), pp. $1-8$.

Imansari, N. and Khadiyanta, P. (2015) 'Penyediaan Hutan Kota dan Taman Kota sebagai Ruang Terbuka Hijau (RTH) Publik Menurut Preferensi Masyarakat di Kawasan Pusat Kota Tangerang', Ruang, 1(3), pp. 101-110. doi: 10.14710/ruang.1.3.101-110.

Renansiva, R. (2018) 'Aplikasi Baja Ringan Pada Konstruksi', Sistem Material dan Peralatan Konstruksi (SIMPK), (Materi Launching Katalog Baja Ringan dan Sistem Informasi Material Peralatan Konstruksi). Available at: http://mpk.binakonstruksi.pu.go.id/upload/file/Launching_Revi_Aplikasi_Produk_Baja_Ringa n_APBRI.pdf.

Widjajanti, W. W. (2010) 'Keberadaan dan Optimasi Ruang Terbuka Hijau Bagi Kehidupan Kota', pp. $1-7$. 